\title{
Modelling of heavy metals adsorption to a chelating resin in a fluidized bed reactor ${ }^{1}$
}

\author{
P. Menoud, L. Cavin, A. Renken* \\ Institute of Chemical Engineering, Swiss Federal Institute of Technology, CH-1015 Lausanne, Switzerland
}

Received 26 June 1997; accepted 7 July 1997

\begin{abstract}
Adsorption to a chelating resin is a method for recovering heavy metals from wastewater containing very light quantities of heavy metals ( $<0.3 \mathrm{~mol} \mathrm{~m}^{-3}$, which approximately corresponds to $20 \mathrm{ppm}$ ). A thermodynamical study in a closed vessel showed that equilibrium is well represented by a Langmuir isotherm. Adsorption kinetics in a continuous stirred tank reactor were also conducted. Experiments were simulated by a global kinetics model comprising mass transfer in a liquid film around the resin particles, with diffusion through the pores and reaction on the adsorption sites. Kinetics has been found to be limited by film mass transfer for all metals studied $\left(\mathrm{Cu}^{2+}, \mathrm{Ni}^{2+}, \mathrm{Co}^{2+}\right.$ and $\left.\mathrm{Zn}^{2+}\right)$. The mass transfer coefficient $k_{\mathrm{L}}$ was found to be around $10^{-4} \mathrm{~m}$ $\mathrm{s}^{-1}$. Adsorption of heavy metals was then carried out at mini-pilot scale. Problems due to a decrease in particles mean radius during the adsorption prompted us to use a fluidized bed. It is also possible with this reactor to treat solutions containing suspended solids which would clog fixed beds. The decrease in particle radius (or increase in apparent density of the resin) produces a contraction of the fluidized bed: unloaded particles remain at the top of the bed and a density gradient appears throughout the column, leading to a stabilization of the fluidized bed. The measured phenomenon is well described by a liquid plug flow model with immobile resin in the column. As for the adsorption in the continuous stirred tank, the Langmuir model and the kinetics limited by film mass transfer were considered. The mass transfer coefficient $k_{\mathrm{L}}$ was adjusted to a value around $10^{-5} \mathrm{~m} \mathrm{~s}^{-1}$. (c) 1998 Elsevier Science S.A.
\end{abstract}

Keywords: Chelating resin; Heavy metal; Langmuir isotherm; Adsorption kinetics; Fluidized bed; Stratification

\section{Introduction}

This work is involved in the development of a new process for the recovery of heavy metals with a chelating resin [1]. Shrinking of the resin during adsorption prompted us to use a fluidized bed reactor instead of a fixed bed [2]. An application in a fluidized bed reactor requires a good understanding of the equilibrium and kinetics properties of the adsorption. Helfferich [3] has shown that the kinetics of adsorption can be described by three kinetics resistances. These are: mass transfer from bulk liquid to the outer surface of the particle (external mass transfer), diffusion into the pores of the particle (internal diffusion) and the chemical reaction on the chelating site. The global adsorption rate can be

\footnotetext{
* Corresponding author. Tel.: +41 21 6933181; fax: +41 21 6933190; e-mail: albert.renken@epfl.ch

${ }^{1}$ Dedicated to Professor K.R. Westerterp on occasion of his 70 th birthday.
}

limited by one or more dominating steps and the other steps can be of less significance. The most important thing is to identify the kinetics limiting step and to measure the kinetic parameters. For instance, Juang and Lin [4] show that the adsorption of copper on a modified macroporous Amberlite XAD resin is limited by pore diffusion. However, they identify that the adsorption of zinc on the same resin is dominated by a coupling of pore diffusion and chemical reaction [5]. Rao and Gupta [6,7] present batch experiments where they interpret copper adsorption on the chelating resin Chelex 100 as limited by external mass transfer when the initial metal concentration $c_{0}=25 \mathrm{ppm}$. They assume a pore diffusion limitation for a metal concentration of $100 \mathrm{ppm}$ and they reach the same conclusions with the adsorption of cadmium for slightly different concentrations $c_{0}$.

The aim of the present paper is to develop a complete model which considers the three resistances. The model 
will be simplified in identifying one or two limiting steps. Then the parameters of the model are determined by optimisation, either by existing correlations or by separate experiments. Several authors proposed the complete or simplified kinetics model for adsorption on solid particles $[3,8-10]$. We will refer to the paper of Horstmann and Chase [11] for the mathematical formalism developed for the adsorption of immunoglobulin on a Protein A fixed on an agarose matrix.

The kinetic model discussed in the first part of the paper will next be applied to the adsorption of metal in a fluidized bed reactor. Most authors in the literature use a plug flow model for fixed bed applications. For instance, Biscans [12] applies this model for the fixed bed adsorption of copper on a Duolite C20D resin. Hydrodynamics characterisation of a fluidized bed is more delicate than for a fixed bed. Slater [10] assumes that liquid axial dispersion depends on the equipment scale and notices a great lack in the literature about this topic. He proposes a simultaneous experimental investigation on hydrodynamics and kinetics to get a realistic view of the process. Biscans [12] and Bascouls [13] think that a plug flow model gives a good description for the liquid phase behaviour.

For several authors $[9,13]$, the solid phase is dominating the behaviour of a liquid-solid fluidized bed. The literature emphasizes three distinct ways to consider the 'non ideality' of the fluidized beds.

- The non ideality of the fluidized bed is included in a liquid axial dispersion coefficient. Draeger and Chase [14] complete the adsorption of BSA on the Q-Sepharose resin in a fluidized bed. They use the plug flow model and propose to introduce liquid axial dispersion to improve the simulation. Hwang and $\mathrm{Lu}$ [15] apply a dispersive model to fixed, fluidized and semi-fluidized beds. They unfortunately do not give the liquid axial dispersion coefficient used in the model. Ito et al. [16] present a dispersive model for the adsorption of uranium in a circulating fluidized bed that they divide in slices. The number of slices, going from 1 to 30 depending on the simulations, does not affect the results significantly. The use of a liquid axial dispersion coefficient to simulate a fluidized bed is questionable, even if the simulation is good: one cannot ignore the solid behaviour, a priori.

- Particles, axial mixing along a fluidized bed column, can be described on the basis of random movements comparable to diffusion phenomena and can be interpreted by Fick's law comprising a solid axial dispersion coefficient. Van der Meer [17] proposes a correlation which binds the axial dispersion coefficient to the superficial liquid velocity. Veeraraghavan and Fan [9] consider the liquid and solid axial dispersion to modelize fluidized beds, although they notice a liquid plug flow behaviour. They suggest however, to maintain the liquid axial dispersion term in order to stabilize numerical calculations.

- Bascoul [18] gives a quantitative description of the organized movement of the solid linked with the superficial velocity in a fluidized bed: the solid goes up in the middle of the column and goes down along the walls. For shallow beds, the solid behaviour corresponds to that of a CSTR. Several authors $[2,12,19-21]$ consider a complete mixing of the solid phase, while the liquid phase is modelized by a plug flow (plug flow model with back mixing of the solid). Carrère [22] also adds the contribution of liquid axial dispersion to that model. Gailliot et al. [23] and Gübeli [24] go further in the simplification of the model and consider the fluidized bed behaviour (liquid and solid phase) to be the same as that of a CSTR (stirred tank reactor model).

\section{Materials and methods}

\subsection{Adsorbent}

The resin used for our application is the Chelamine Standard ${ }^{\circledR}$ (JPS-Chimie, Neuchâtel, Switzerland). It is synthesized using a polyacrylamide gel and tetraethylene pentamine chelating groups [25]. Before each use, the resin is treated in a fixed bed with a solution of sulfuric acid ( $\mathrm{pH} 1.0)$, then washed with demineralized water. In further steps, the resin undergoes a regeneration with a sodium hydroxide solution $(\mathrm{pH} 11.5)$ and a wash with demineralized water until a defined $\mathrm{pH}\left(\mathrm{pH}_{0}\right)$ in the effluent is obtained. If not mentioned otherwise, $\mathrm{pH}_{0}=11.0$. For equilibrium and kinetics experiments, the resin was dried during $24 \mathrm{~h}$ at $60^{\circ} \mathrm{C}$.

The mean radius of the particles $r_{\mathrm{p}}$ was measured by laser diffraction (Particle Sizer 2600 E, Malvern Instruments, England) for unloaded and loaded resins. The porosity of the particles was determined by the measurement of the residence time distribution of two void volume markers in a fixed bed: Dextran T2000 (Pharmacia LKB, Uppsala, Sweden) was used to measure the void volume between the resin particles and $\beta-\mathrm{D}(+)$ glucose (Sigma, St. Louis) giving the total void volume in the fixed bed. The porosity of the fixed bed of resin $\varepsilon_{0}$ and the particle porosity $\varepsilon_{\mathrm{p}}$ were estimated from the experimentally obtained mean residence times of the tracers.

Table 1 gives a summary of the physical properties of the resin Chelamine (unloaded and loaded resin).

The apparent density of the resin $\rho_{\text {ap }}$ was calculated using the Schiller-Naumann [26] correlation and the mass of dry resin per unit volume of swollen particle $\rho_{\mathrm{p}}$. 
Table 1

Physical properties of the resin Chelamine

\begin{tabular}{lllllll}
\hline & $\begin{array}{l}\text { Particle mean radius } \\
r_{\mathrm{p}} 10^{4}(\mathrm{~m})\end{array}$ & $\begin{array}{l}\text { Fixed bed porosity } \\
\varepsilon_{0}\end{array}$ & $\begin{array}{l}\text { Particle porosity } \\
\varepsilon_{\mathrm{p}}\end{array}$ & $\begin{array}{l}\rho_{\mathrm{p}} \\
\left(\mathrm{kg} \mathrm{m}^{-3}\right)\end{array}$ & $\begin{array}{l}\text { Archimedes } \\
\text { number }\end{array}$ & $\begin{array}{l}\rho_{\text {ap }} \\
\left(\mathrm{kg} \mathrm{m}^{-3}\right)\end{array}$ \\
\hline $\begin{array}{l}\text { Unloaded resin } \\
\text { Loaded resin } \\
\left(\mathrm{Cu}^{2+}\right)\end{array}$ & $1.730 \pm 0.003$ & $0.33 \pm 0.003$ & $0.81 \pm 0.01$ & $158.4 \pm 3.6$ & $30 \pm 6$ \\
\hline
\end{tabular}

\subsection{Adsorbate}

The metal cations were used as sulfates purchased from Fluka AG (Buchs, Switzerland). As industrial waste waters are not buffered, heavy metal solutions contained only hydrated metal salts.

\subsection{Adsorption equilibrium studies}

A quantity of dry resin $m\left(0.4 \times 10^{-3} \mathrm{~kg}\right)$ and a volume $V\left(4 \times 10^{-5} \mathrm{~m}^{3}\right)$ of metal solutions, with initial concentrations $c_{0}$, were put in a plastic flask. The vials were stirred in a constant temperature bath at $20^{\circ} \mathrm{C}$ for $24 \mathrm{~h}$. The equilibrated solutions were filtered and analysed by atomic absorption spectrometry, which was used to determine their equilibrium concentrations $c^{*}$. The equilibrium solute concentration $q^{*}$ on the solid was calculated by the mass balance.

\subsection{Adsorption kinetics}

Continuous stirred tank reactor (CSTR) and fluidized bed adsorption experiments were conducted in the same installation (Fig. 1), this which included the adsorption reactor (CSTR or fluidized bed), two tanks located $14 \mathrm{~m}$ above the reactor and a samples collector. One tank was filled with demineralized water and the other one contained the metal solution. The flow rate $Q$ was regulated by a valve, whose stability was checked with a rotameter. The inlet flow and the reactor were thermostated at $20.0^{\circ} \mathrm{C}$, with a heat exchanger and a double jacket, respectively. The reactor contained a quantity $m$ of resin, which was washed with demineralized water and the experiment started when valve 1 was switched. The liquid leaving the reactor passed through a sampling system. The concentration $c$ of each sample was analysed by atomic absorption spectrometry. The solution was then collected in a retention tank.

The glass CSTR had a volume of $3.6 \times 10^{-4} \mathrm{~m}^{3}$ $\left(6.6 \times 10^{-2} \mathrm{~m}\right.$ inner diameter) and it was mechanically stirred by an impeller $\left(3.3 \times 10^{-2} \mathrm{~m}\right.$ diameter $)$. The residence time distribution of a tracer (step injection) showed that this reactor can be considered as an ideal CSTR, for an adsorption duration of about $4 \mathrm{~h}$.

\subsection{Fluidized bed adsorption}

The fluidized bed column (Fig. 2) $\left(5.2 \times 10^{-2} \mathrm{~m}\right.$ inner diameter) comprised up to five Plexiglas elements (0.102 $\mathrm{m}$ height). Underneath the very bottom of the column was a distributor filled with glass beads (mean radius: $2.1 \times 10^{-3} \mathrm{~m}$ ), which was covered with a $40 \mu \mathrm{m}$ filter. An identical filter prevented small resin particles from leaving the column. Temperature was measured every $10 \mathrm{~cm}$ from the bottom to the top of the column and a value of $20.0 \pm 0.5^{\circ} \mathrm{C}$ was always guaranteed.

\section{Experimental results and discussion}

\subsection{Adsorption equilibrium study}

Equilibrium isotherms were measured for the adsorption of four metals on the resin Chelamine: copper, nickel, zinc and cobalt. The adsorption of a metallic cation $\mathrm{M}^{2+}$ on a chelating resin can be represented by the following equation:

$\mathrm{R}+\mathrm{M}^{2+} \underset{\overrightarrow{k_{\mathrm{r}}}}{\stackrel{k_{\mathrm{f}}}{\rightleftharpoons}} \mathrm{RM}^{2+}$

The model implies a second-order reversible interaction, where $\mathrm{R}$ is a free adsorption site and $\mathrm{RM}^{2+}$ an occupied site. The parameters $k_{\mathrm{f}}$ and $k_{\mathrm{r}}$ are the forward and reverse rate constants. The rate of adsorption is given by the balance for the batch system:

$\frac{\mathrm{d} q_{i}}{\mathrm{~d} t}=k_{\mathrm{f}} c_{i}\left(q_{\mathrm{m}}-q_{i}\right)-k_{\mathrm{r}} q_{i}$

where $c_{i}$ and $q_{i}$ represent the solute concentrations in the liquid pore and in the resin and $q_{\mathrm{m}}$ is the maximum capacity of the resin. If the mass action law is applied to Eq. (1), the Langmuir isotherm model is obtained:

$\frac{q^{*}}{q_{\mathrm{m}}}=\frac{c^{*}}{K_{\mathrm{d}}+c^{*}}$

where $c^{*}$ and $q^{*}$ are the equilibrium metal concentrations in the solution and on the resin, respectively; $K_{\mathrm{d}}$ is the dissociation constant given by:

$K_{\mathrm{d}}=\frac{k_{\mathrm{r}}}{k_{\mathrm{f}}}$ 


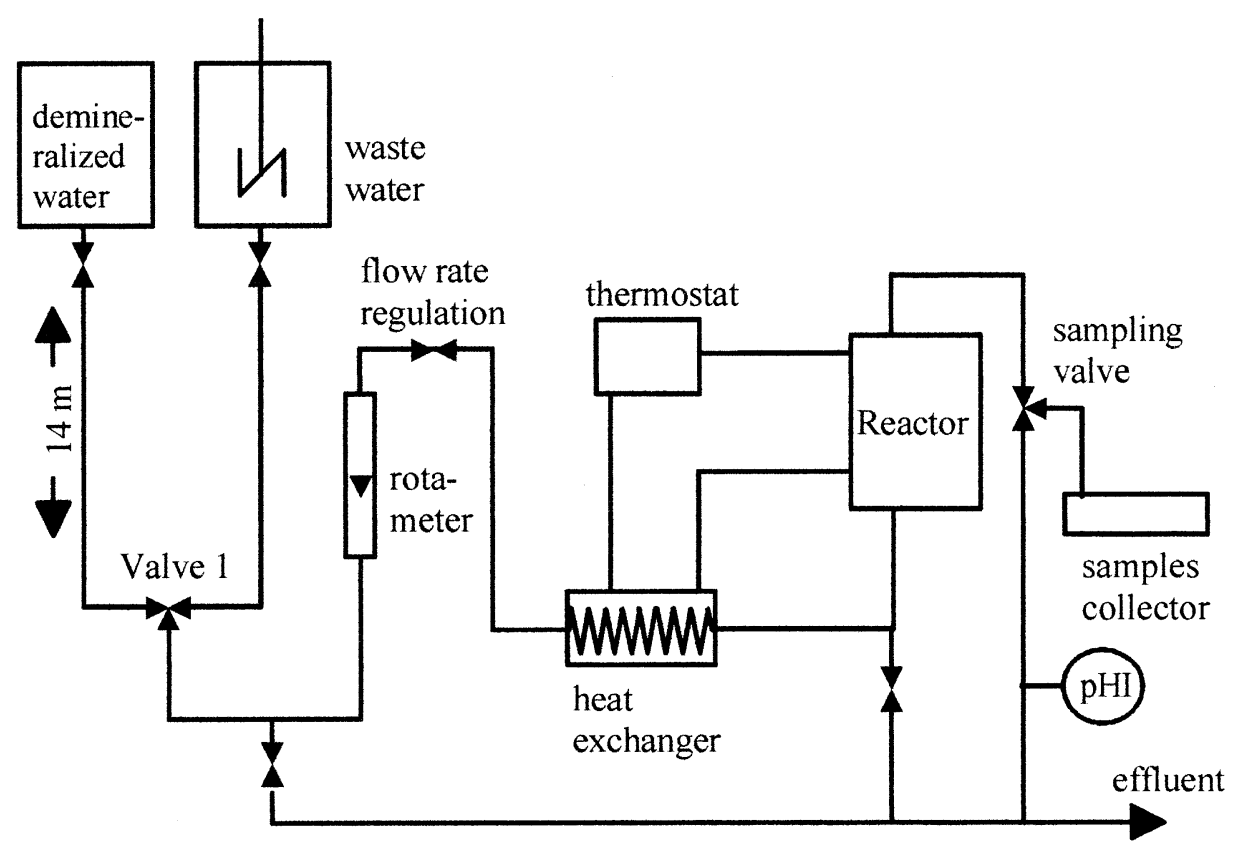

Fig. 1. Schematic diagram of experimental apparatus.

The adsorption isotherms obtained were found to fit well to the Langmuir expression (Eq. (3)). An analysis of the obtained parameters leads to the following results: the resin capacity $q_{\mathrm{m}}$ is between 0.8 and $1.0 \mathrm{~mol}$

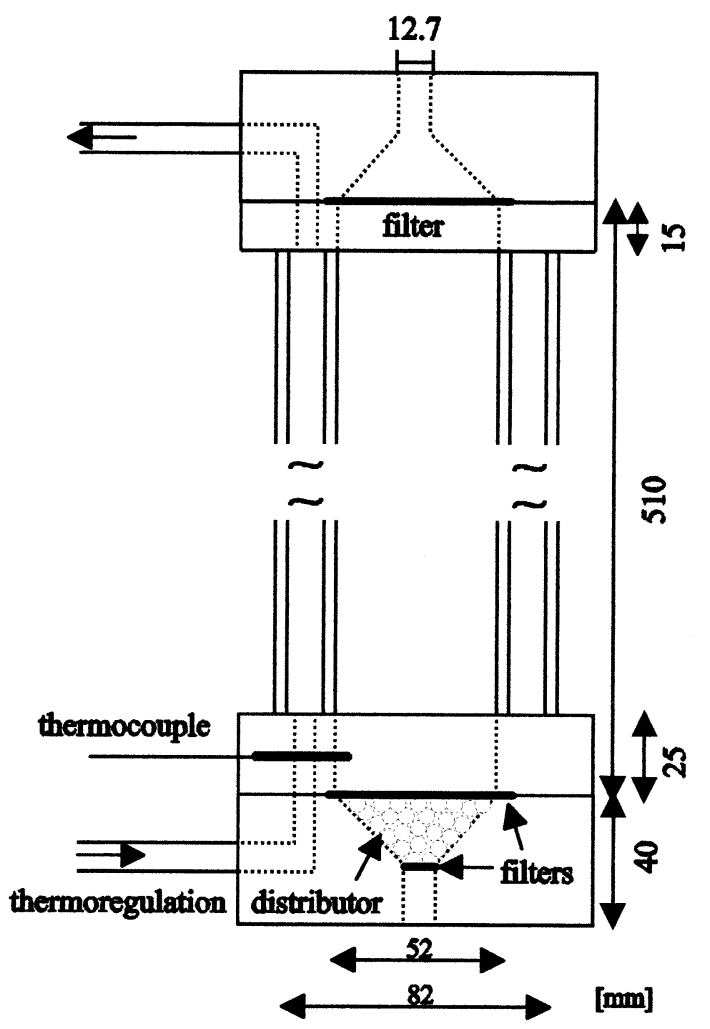

Fig. 2. Schematic diagram of the fluidized bed reactor. $\mathrm{kg}^{-1}$. The dissociation constant $K_{\mathrm{d}}$ is of the same order $\left(10^{-2} \mathrm{~mol} \mathrm{~m}^{-3}\right)$ for all different metals studied: The equilibrium is very favourable in all cases. CSTR and fluidized bed experiments dealt with solutions containing less than $0.3 \mathrm{~mol} \mathrm{~m}^{-3}$. The use of the whole Langmuir model is required to represent the equilibrium.

The Langmuir isotherm for the adsorption of copper to the resin Chelamine, shown in Fig. 3, gives a dissociation constant $K_{\mathrm{d}}$ of $0.007 \mathrm{~mol} \mathrm{~m}^{-3}$ and $0.97 \mathrm{~mol} \mathrm{~kg}^{-1}$ for the resin capacity. For instance, as the resin load is $80 \%$, the equilibrium copper concentration in solution is still very low $\left(0.03 \mathrm{~mol} \mathrm{~m}^{-3}\right.$ or $\left.1.9 \mathrm{ppm}\right)$, due to the very favourable equilibrium behaviour.

\subsection{Adsorption kinetics}

Fig. 4 shows a typical response to a stepwise concentration change at the inlet of the CSTR. The metal concentration is related to the inlet value and the time is related to the mean residence time, defined with the molar capacity of the resin as follows [27]:

$f=\frac{c}{c_{0}} ; \quad \theta=\frac{t}{\tau_{\mathrm{m}}}=\frac{Q c_{0} t}{m q_{0}}$

where $c_{0}$ is the inlet concentration and $c$ is the bulk concentration. The mean residence time $\tau_{\mathrm{m}}$ is the ratio between the total molar capacity of the resin and the inlet molar flow rate. $Q$ is the flow rate; $m$ is the mass of the resin. $q_{0}$, the metal concentration on the resin, is calculated with the following formula: 


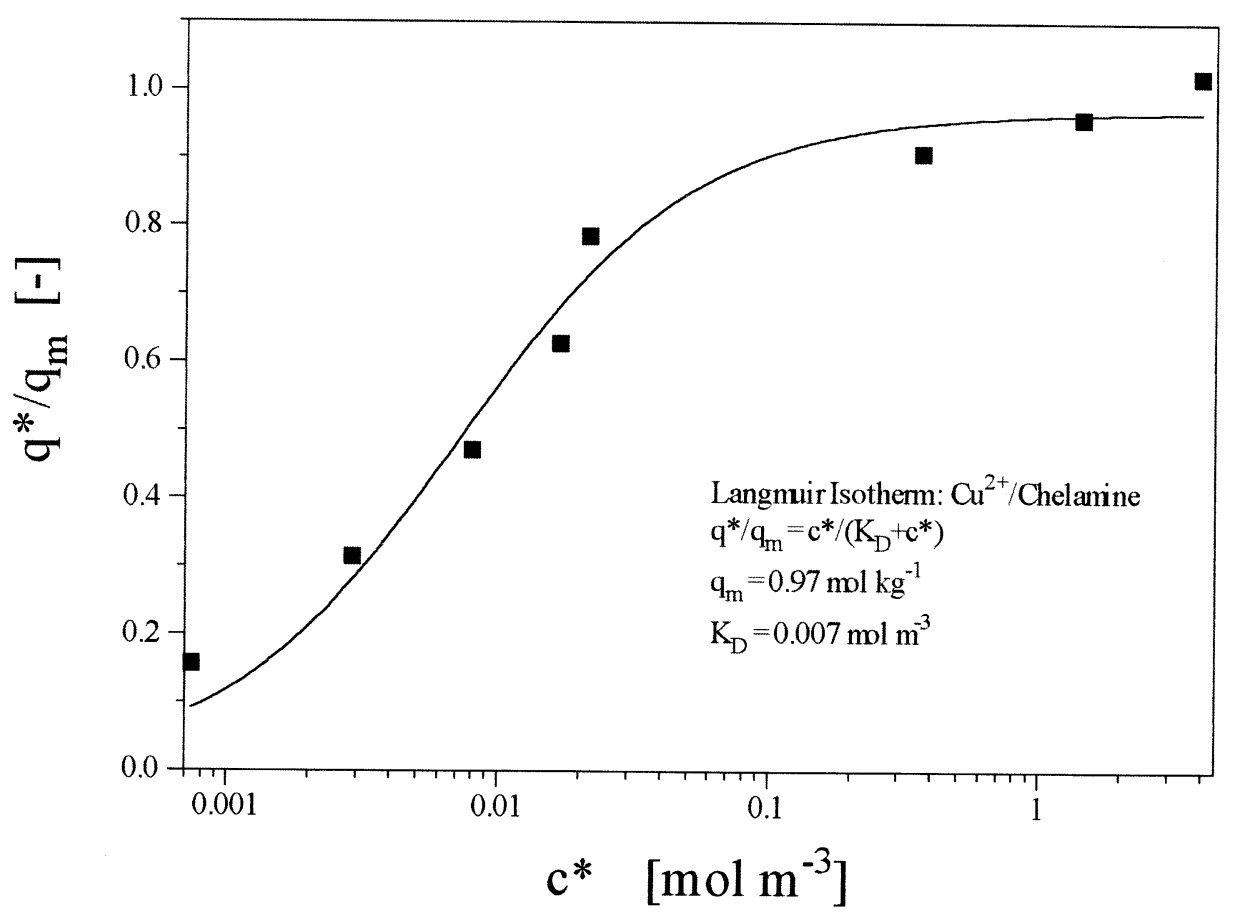

Fig. 3. Equilibrium isotherm for the adsorption of copper by the resin Chelamine.

$q_{0}=\frac{Q}{m}\left(\int_{0}^{\infty}\left(c_{0}-c\right) \mathrm{d} t-\tau c_{0}\right)$

The space time $\tau$ is:

$\tau=\frac{\varepsilon_{\mathrm{r}} V}{Q}$

Operating conditions for the results, shown in Fig. 4, are detailed in Table 2. At the beginning of the run, the concentration $f$ changed to a value of 0.06 and then increased gently until the end of the run, where the curve adopts an 's' shape, which indicates the saturation of the resin.

The global kinetic model describes the adsorption of a metallic cation $\mathbf{M}^{2+}$ in solution by a porous chelating resin. We assume that the resin particles are spherical and that their radius $r_{\mathrm{p}}$ and density $\rho_{\mathrm{p}}$ are uniform. The global kinetics process comprises three steps considered as three resistances:

1. Mass transfer of $\mathbf{M}^{2+}$ from the bulk of the solution to the surface of the particle. The mass transfer rate is proportional to the concentration linear gradient between the bulk and the surface concentrations. The proportionality factor is the external transfer coefficient $k_{\mathrm{L}}$.

2. Diffusion of $\mathbf{M}^{2+}$ in the liquid of the resin pores. The phenomenon is described by the first Fick's law, where the important parameter is the effective diffusion coefficient $D^{\mathrm{e}}$. This coefficient, which does not depend on concentration, includes the diffusivity coefficient at infinite dilution $D_{\mathrm{L}}$, the internal porosity $\varepsilon_{\mathrm{p}}$ and the effect of the pores tortuosity.
3. Complexation reaction on the chelating sites. This step has already been presented in the equilibrium study above by Eq. (2).

At the surface of the particle, at distance $r$ from the centre of a particle, the rate of external mass transfer through the film relates the bulk concentration to the pore liquid concentration at the surface of the particle.

$r=\left.r_{\mathrm{p}} \quad D^{\mathrm{e}} \frac{\mathrm{d} c_{i}\left(r_{\mathrm{p}}\right)}{\mathrm{d} r}\right|_{r_{\mathrm{p}}}=k_{\mathrm{L}}\left(c-c_{i}\left(r_{\mathrm{p}}\right)\right)$

At the centre of the particle, the symmetry of the system implies:

$r=\left.0 \quad \frac{\mathrm{d} c_{i}(0)}{\mathrm{d} r}\right|_{0}=0$

A differential mass balance on $\mathrm{M}^{2+}$, at distance $r$ from the centre of a particle and at time $t$, leads to:

$\varepsilon_{\mathrm{p}} \frac{\partial c_{i}}{\partial t}=D^{\mathrm{e}}\left(\frac{\partial^{2} c_{i}}{\partial r^{2}}+\frac{2}{r} \frac{\partial c_{i}}{\partial r}\right)-\rho_{\mathrm{p}} \frac{\partial q_{i}}{\partial t}$

where $\rho_{\mathrm{p}}$ is the mass of dry resin per unit volume of swollen resin. Adsorption in a continuous stirred tank reactor is described by the following mass balance:

$\frac{\mathrm{d} c}{\mathrm{~d} t}=\frac{1}{\tau}\left(c_{0}-c\right)-\frac{k_{\mathrm{L}} a}{\varepsilon_{\mathrm{r}}}\left(c-c_{i}\left(r_{\mathrm{p}}\right)\right)$

The initial condition $(t=0)$ of the concentration $c$, in Eq. (11), is set at zero.

If the liquid inside the particles is neglected, compared to the total CSTR volume $V$, the reactor porosity $\varepsilon_{\mathrm{r}}$ becomes: 


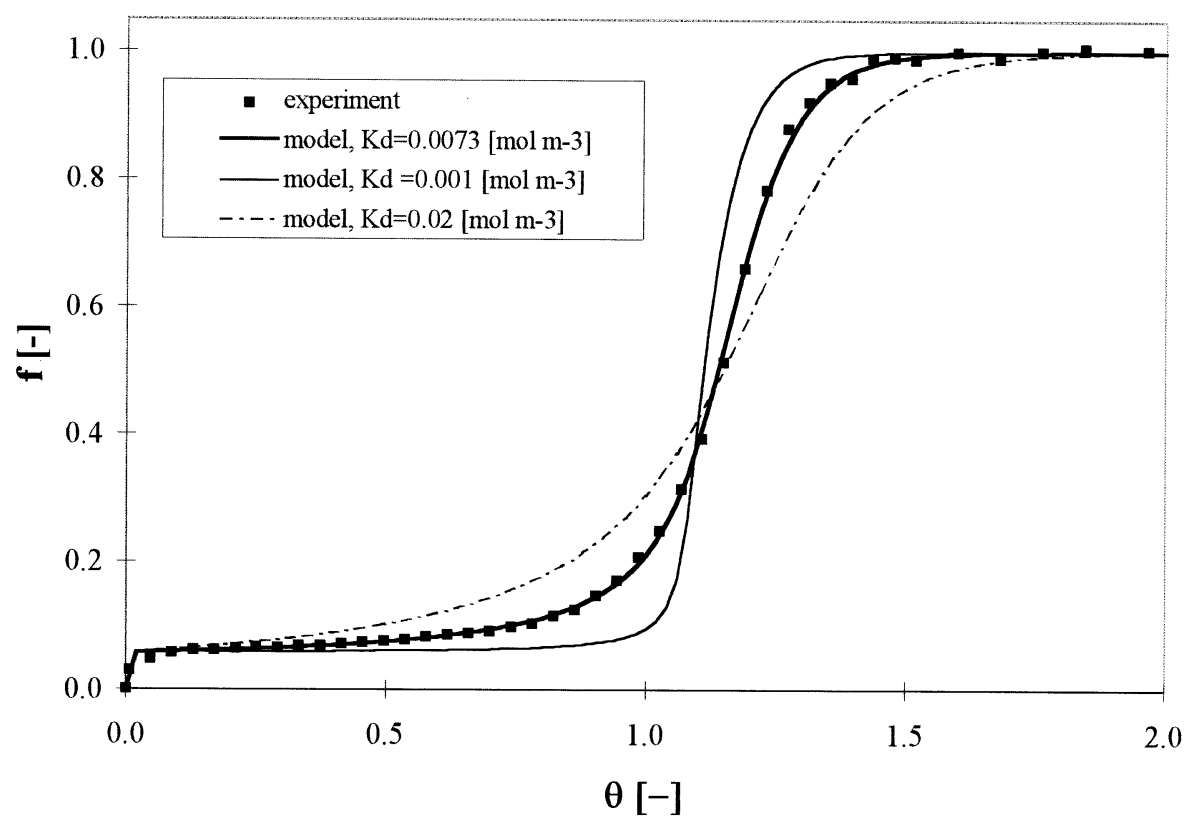

Fig. 4. Adsorption of nickel to the Chelamine resin. Model with external transfer limitation; influence of the dissociation constant $K_{\mathrm{d}}$ on the adsorption kinetics of nickel; $k_{\mathrm{L}}=9.74 \times 10^{-5} \mathrm{~m} \mathrm{~s}^{-1}, c_{0}=0.3185 \mathrm{~mol} \mathrm{~m}^{-3}, Q=1.074 \times 10^{-6} \mathrm{~m}^{3} \mathrm{~s}^{-1}, m=0.00211 \mathrm{~kg}$.

$\varepsilon_{\mathrm{r}}=1-\frac{m}{V \rho_{\mathrm{p}}}$

The surface of the particles per reactor unit volume $a$ and the number of particles present in the reactor $n_{\mathrm{p}}$ are defined by, respectively:

$a=\frac{4 \pi r_{\mathrm{p}}^{2} n_{\mathrm{p}}}{V}$

$n_{\mathrm{p}}=\frac{3 m}{4 \pi r_{\mathrm{p}}^{3} \rho_{\mathrm{p}}}$

Numerical solutions of the differential equations for the different models developed here, were obtained with the software Simusolv (Dow Chemical, Midland, MI). The integration method used was a Gear algorithm (BDF-DIFSUB) with variable step and order.

Table 2

Parameters for CSTR experiments; adsorption to the resin Chelamine

\begin{tabular}{lcccc}
\hline & $\mathrm{Cu}^{2+}$ & $\mathrm{Ni}^{2+}$ & $\mathrm{Zn}^{2+}$ & $\mathrm{Co}^{2+}$ \\
\hline $\begin{array}{l}c_{0} \\
\left(\mathrm{~mol} \mathrm{~m}^{-3}\right)\end{array}$ & 0.323 & 0.319 & 0.320 & 0.350 \\
$Q$ & $9.19 \times 10^{-7}$ & $1.074 \times 10^{-6}$ & $1.125 \times 10^{-6}$ & $1.182 \times 10^{-6}$ \\
$\left(\mathrm{~m}^{3} \mathrm{~s}^{-1}\right)$ & 11.0 & 11.0 & 9.5 & 9.5 \\
$\mathrm{pH}_{0}$ & 1.16 & 0.95 & 0.86 & 0.83 \\
$\begin{array}{l}q_{0} \\
\left(\mathrm{~mol} \mathrm{~kg}^{-1}\right)\end{array}$ & 0.0067 & 0.0073 & 0.0082 & 0.0109 \\
$\begin{array}{l}K_{\mathrm{d}} \\
\left.(\mathrm{mol} \mathrm{m})^{-3}\right)\end{array}$ & 13.1 & 16.3 & 17.2 & 16.2 \\
$\mathrm{DaI}$ & & &
\end{tabular}

$m=0.00211 \mathrm{~kg} ; k_{\mathrm{L}}=7.0 \times 10^{-5}$ to $1.1 \times 10^{-4} \mathrm{~m} \mathrm{~s}^{-1}$.
The typical adsorption result shown in Fig. 4 is analysed with the global kinetic model, by assuming that only one of the three resistances governs the adsorption rate: the model parameters of the other two resistances are fixed to suitably high values.

Evaluation of the experimental result shows that the external mass transfer is rate limiting. The precision of the results is improved by calculating the number of particles $n_{\mathrm{p}}$, with the radius of the unloaded particle $r_{\mathrm{p}}$ $\left(1.730 \times 10^{-4} \mathrm{~m}\right)$ and the surface of the particles per reactor unit volume $a$ with the average radius between loaded and unloaded particles $\left(1.524 \times 10^{-4} \mathrm{~m}\right.$, Table $1)$.

The model with an external transfer limitation gives an excellent representation of the experimental data (Fig. 4). It shows a high sensitivity to the parameters $K_{\mathrm{d}}$ and $k_{\mathrm{L}}$. The validity of the model with external mass transfer limitation has been extended to the adsorption of different heavy metals to resin Chelamine. Table 2 gives the experimental conditions and the adjusted model parameters for the metallic cations tested, which are copper, nickel (already discussed), cobalt and zinc. Figs. 5 and 6 show experimental results and expected results for the various metallic cations.

The dissociation constant $K_{\mathrm{d}}$ is estimated for each experiment. $K_{\mathrm{d}}$, determined from experiments is in good agreement with values obtained from equilibrium measurements. The values are dependent on the $\mathrm{pH}$ values. The CSTR procedure developed here was considered for the experimental determination of constant $K_{\mathrm{d}} \cdot k_{\mathrm{L}}$ for all runs was very close and the mean value was $k_{\mathrm{L}}=0.96 \times 10^{-4} \mathrm{~m} \mathrm{~s}^{-1}$. The $k_{\mathrm{L}}$ values are in accordance with those given in the literature. 


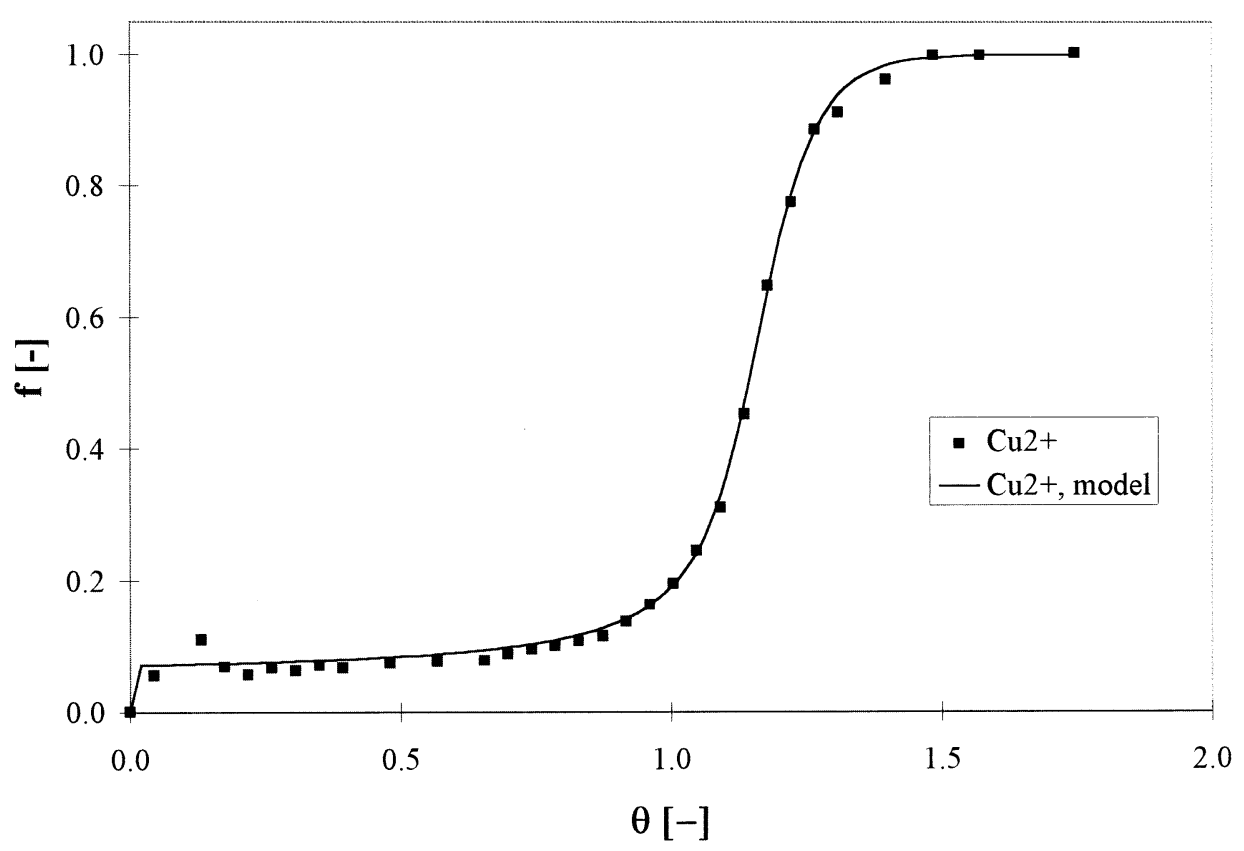

Fig. 5. Adsorption of copper in a CSTR; $K_{\mathrm{d}}=0.0067 \mathrm{~mol} \mathrm{~m}^{-3}, k_{\mathrm{L}}=7.110^{-5} \mathrm{~m} \mathrm{~s}^{-1}, c_{0}=0.323 \mathrm{~mol} \mathrm{~m}^{-3}, Q=9.194 \times 10^{-7} \mathrm{~m}^{3} \mathrm{~s}^{-1}$, $m=0.00211 \mathrm{~kg}$.

The adsorption rate for low concentration heavy metal solutions to the resin Chelamine is governed by external mass transfer and the parameter to consider is the mass transfer coefficient $k_{\mathrm{L}}$. The coefficient $k_{\mathrm{L}}$ can be integrated in a more general parameter, the Damköhler number I, defined as the ratio of the residence time $\tau$ to the characteristic time of the mass transfer:

$\mathrm{DaI}=\frac{k_{\mathrm{L}} a \tau}{\varepsilon_{\mathrm{r}}}$

With an adsorption model of external transfer limitation, the concentration profile at the outlet of a CSTR is fully described by the parameters $\mathrm{DaI}$ and $K_{\mathrm{d}}$. The number DaI, determines the height of the initial plateau of the $f$-curve. A large DaI (high transfer rate compared to residence time) will lower the plateau of the $f$-curve and thus, minimize metal loss at the outlet of the reactor. Notice that the surface between the curve where $\mathrm{DaI}=0\left(k_{\mathrm{L}}=0\right)$ and any other simulated curve is equal to 1 .

The dissociation constant $K_{\mathrm{d}}$ has an effect on the 's' shape of the $f$-curve (Fig. 4). An unfavourable equilibrium (high value of $K_{\mathrm{d}}$ ), tends to distort the 's' in stretching the $f$-curve in time and thus, to raise the plateau at the beginning of adsorption. The importance of a favourable equilibrium in an adsorption process is easily seen here.

The stability constants of complexes of heavy metals to the Chelamine resin gave the following sequence for CSTR experiments:
$\mathrm{Cu}^{2+}>\mathrm{Ni}^{2+}>\mathrm{Zn}^{2+}>\mathrm{Co}^{2+}$

The same sequence was obtained for complexes of heavy metals to tetraethylene pentamine (chelating group of the Chelamine resin) at $\mathrm{T}=20^{\circ} \mathrm{C}$ [28].

Blain et al. [29] obtained a comparable sequence from the adsorption of a mixture of copper, nickel and zinc to the resin Chelamine. Schmidt [2] confirmed this result for batch isotherms with solutions containing $\mathrm{NaNO}_{3}(0.2 \mathrm{M})$.

Harriott [30] determined a mass transfer coefficient in a batch stirred tank for the neutralisation of the resin DOWEX 50 WX8: for a particle with a mean radius of $1.5 \times 10^{-4} \mathrm{~m}$, the coefficient $k_{\mathrm{L}}$ was $1.20 \times 10^{-4} \mathrm{~m}$ $\mathrm{s}^{-1}$. Metzdorf [31] reproduced this ion exchange reaction under the same conditions in a CSTR and obtained a $k_{\mathrm{L}}$ value of $1.08 \times 10^{-4} \mathrm{~m} \mathrm{~s}^{-1}$. Rao et al. [7] described the adsorption of $\mathrm{Cd}^{2+}$ and $\mathrm{Pb}^{2+}$ on the resin Chelex 100 in a batch system $\left(350 \mathrm{~min}^{-1}\right)$. For low initial concentrations of $c_{0}\left(10 \mathrm{ppm}\right.$ for $\mathrm{Cd}^{2+}$ and $82 \mathrm{ppm}$ for $\mathrm{Pb}^{2+}$ ), the coefficients $k_{\mathrm{L}}$ were $3.610^{-5}$ and $5.510^{-5} \mathrm{~m} \mathrm{~s}^{-1}$.

The mass transfer coefficient $k_{\mathrm{L}}$ determined for the system Chelamine/ $\mathrm{M}^{2+}$ has the same order of magnitude as those obtained for other ion exchange systems.

\subsection{Fluidized bed adsorption}

The adsorption behaviour of copper in conjunction with the resin Chelamine in a fluidized bed is characterized in Fig. 7. The same adsorption was repeated under similar experimental conditions (Runs 1-4) which are 


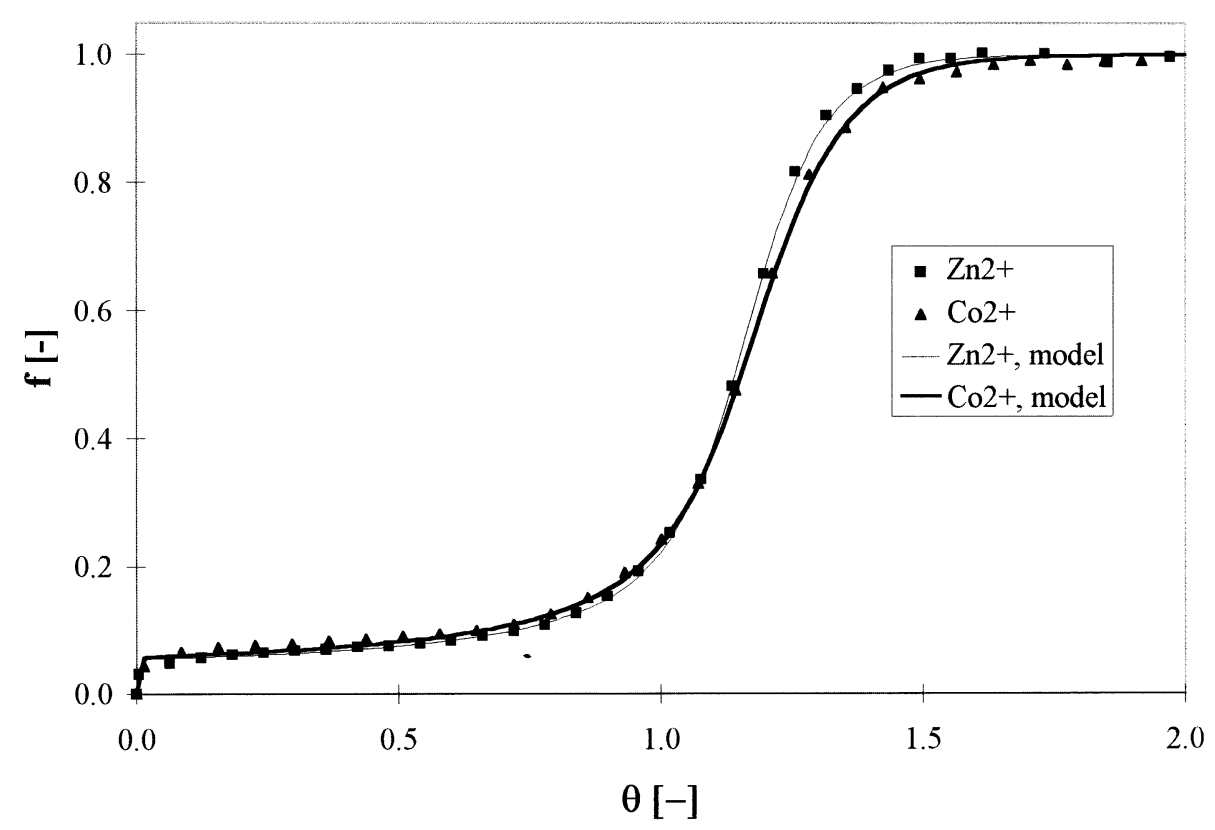

Fig. 6. Adsorption in a CSTR of zinc, $K_{\mathrm{d}}=0.0082 \mathrm{~mol} \mathrm{~m}^{-3}, k_{\mathrm{L}}=1.084 \times 10^{-4} \mathrm{~m} \mathrm{~s}^{-1}, c_{0}=0.320 \mathrm{~mol} \mathrm{~m}^{-3}, Q=1.12510^{-6} \mathrm{~m}^{3} \mathrm{~s}^{-1}$, $m=0.00211 \mathrm{~kg}$ and cobalt, $K_{\mathrm{d}}=0.0109 \mathrm{~mol} \mathrm{~m}{ }^{-3}, k_{\mathrm{L}}=1.06 \times 10^{-4} \mathrm{~m} \mathrm{~s}^{-1}, c_{0}=0.350 \mathrm{~mol} \mathrm{~m}^{-3}, Q=1.182 \times 10^{-6} \mathrm{~m}^{3} \mathrm{~s}^{-1}, m^{-1}=0.00211 \mathrm{~kg}$.

given in Table 3. During $\sim 30 \mathrm{~h}(\theta<0.9)$ before the breakthrough, the outlet concentration was far below Swiss water quality standards ( $0.5 \mathrm{ppm}$ for copper) [32]: it tended towards values approaching the detection limit of the analysis method used $\left(10^{-2} \mathrm{ppm}\right)$. The curve then adopts an 's' shape, as for CSTR adsorption, and finally reaches a plateau corresponding to the saturation of the resin. Notice that, for instance in Run 2, $0.11 \mathrm{~m}^{3}$ of copper solution (concentration $c_{0}=0.302$ mol m $\mathrm{m}^{-3}=19.2 \mathrm{ppm}$ ) was purified to better the water quality standard in about $30 \mathrm{~h}$.

Fig. 7 shows the good reproducibility of adsorption experiments carried out under similar experimental conditions. The first three runs corresponded to three consecutive resin utilisation cycles: at the end of each adsorption, the resin was submitted to an acid desorption and an alkaline regeneration. The resin Chelamine stood up well to these experimental conditions with no loss of capacity $q_{\mathrm{m}}$ and no evident difference in the adsorption profiles observed. The little differences concerning the 's' shape of the breakthrough curve arise certainly from small hydrodynamic instabilities of the fluidized bed.

At the beginning of the adsorption $(1-2 \mathrm{~h})$, the progress of a concentration front was visually observed upwards through the bed: loaded particles (blue) stayed at the bottom of the bed, while the resin above the front remained yellow (unloaded particles). All the resin particles became green after a certain time, turning dark blue later. Thus, it was possible to follow the adsorption by the colour change of the resin only during the initial stage of the experiment.
A decrease in the fluidized bed height with the progress of adsorption was observed. The bed height, $h$ was $3 \times 10^{-1} \mathrm{~m}$ for run 2 at the start of the adsorption and it was $2 \times 10^{-2} \mathrm{~m}$ shorter after $2 \mathrm{~h}$ of running. At the breakthrough point (after $30 \mathrm{~h}$ ), the fluidized height was only $6 \times 10^{-2} \mathrm{~m}$ and the corresponding settled bed height was $5 \times 10^{-2} \mathrm{~m}$ (the initial settled bed height $h_{0}$ was $\left.1.55 \times 10^{-1} \mathrm{~m}\right)$. The stratification of the fluidized bed was due to the contraction of the resin particles during the metal adsorption. As already mentioned in Table 1, a difference of $25 \%$ in the resin mean radius is observed between the unloaded and loaded particles. The apparent density of resin thus increased when the particles were loaded and it corresponds to an increase in the Archimedes number for the loaded particles of about 25. This favourable behaviour of the Chelamine resin in the physical properties allows stabilisation of the fluidized bed, even at very low flow rates $\left(5 \times 10^{-4}\right.$ $\mathrm{m} \mathrm{s}^{-1}$ ).

The decrease in the particles mean radius during metal adsorption resulted in the change of several parameters that the models considered constant:

- The Archimedes number increased and the bed height decreased. The affected parameters are: porosity $\varepsilon_{\mathrm{r}}$ and volume, $V$ of the reactor (included in the residence time $\tau$ ).

- The decrease in particles mean radius $r_{\mathrm{p}}$ reduced the surface of the particles per reactor unit volume $a$ and increased the apparent density $\rho_{\text {ap }}$.

Therefore an average value of radii between loaded and unloaded particles was used to calculate the surface a. 


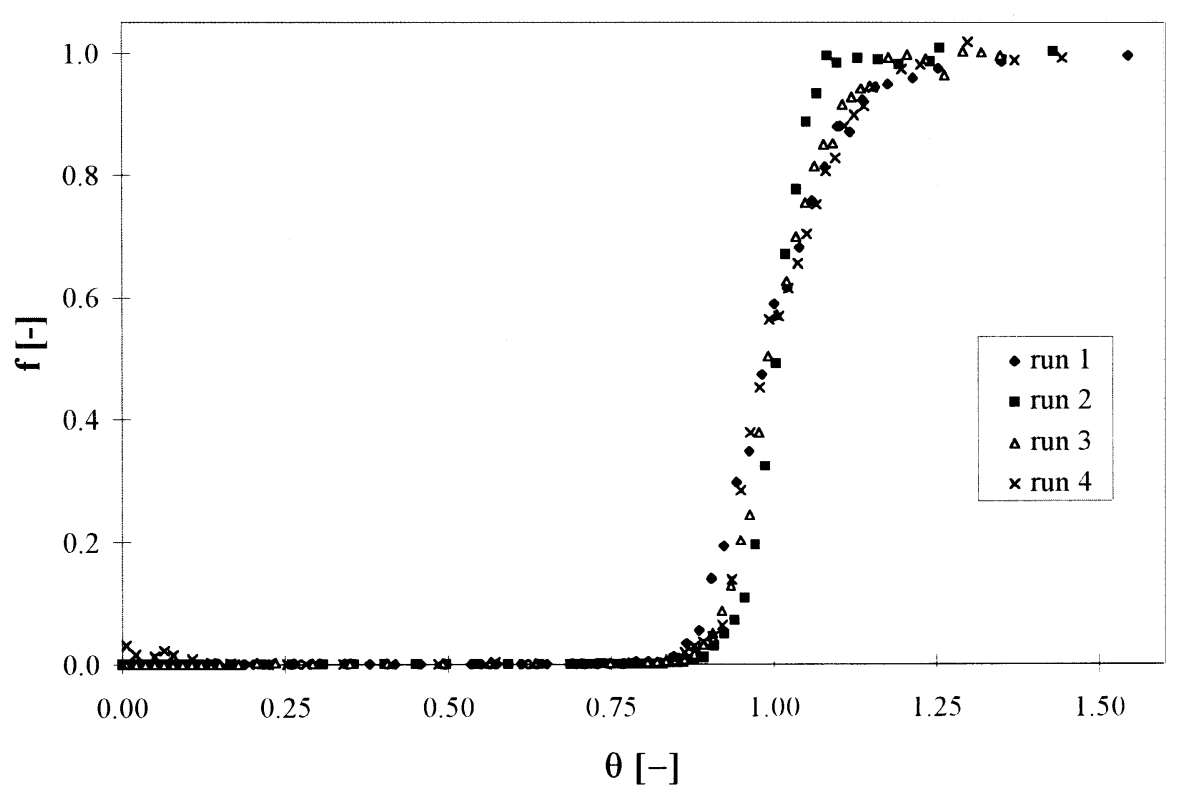

Fig. 7. Adsorption of copper to the resin Chelamine in a fluidized bed (Run 1 to 4) (Table 3).

The adsorption of heavy metals (low concentrations) to the resin Chelamine is governed by external transfer in a CSTR reactor. External mass transfer is, however, sensitive to hydrodynamic conditions and convection is smaller in a fluidized bed than in a CSTR with strong mechanical stirring. It can reasonably be concluded that the kinetic limiting phenomenon in a fluidized bed reactor is a fortiori external transfer and that $k_{\mathrm{L}}$ values are lower than those obtained for CSTR adsorption. All the hydrodynamic models developed below are now applied with external transfer kinetics.

Three models of the reactor can be considered:

(1) Complete back mixing of the liquid and solid, which is the stirred tank reactor model

Adsorption in a continuous stirred tank reactor is described by Eqs. (11)-(14), already presented in the CSTR studies.

Table 3

Parameters for fluidized bed experiments; adsorption of copper to the resin Chelamine

\begin{tabular}{lcccc}
\hline Run & 1 & \multicolumn{2}{c}{3} & \multicolumn{2}{l}{4} \\
\hline $\begin{array}{l}c_{0} \\
\left(\mathrm{~mol} \mathrm{~m}^{-3}\right)\end{array}$ & 0.308 & 0.302 & 0.303 & 0.280 \\
$Q$ & $1.247 \times 10^{-6}$ & $1.053 \times 10^{-6}$ & $9.94 \times 10^{-7}$ & $9.14 \times 10^{-7}$ \\
$\left(\mathrm{~m}^{3} \mathrm{~s}^{-1}\right)$ & & & & \\
$\mathrm{pH}_{0}$ & 11.0 & 10.9 & 11.4 & 10.8 \\
$q_{0}$ & 1.04 & 1.06 & 1.11 & 0.93 \\
$(\mathrm{~mol} \mathrm{~kg}$ & & & \\
$h_{0}(\mathrm{~m})$ & 0.149 & 0.155 & 0.150 & 0.140 \\
$h(\mathrm{~m})$ & 0.310 & 0.300 & 0.290 & 0.275 \\
DaI & 23.2 & 55.0 & 35.0 & 31.7 \\
\hline
\end{tabular}

$m=0.03411 \mathrm{~kg} ; k_{\mathrm{L}}=1.0-2.0 \times 10^{-5} \mathrm{~m} \mathrm{~s}^{-1} ; K_{\mathrm{d}}=0.0067 \mathrm{~mol} \mathrm{~m}^{-3}$.
(2) Nearly plug flow of the liquid and a complete back mixing of the solid, which is the plug flow model with back mixing of the solid.

The equation of continuity in the mobile phase is given by:

$u \frac{\partial c}{\partial z}+\left(1-\varepsilon_{r}\right) \rho_{\mathrm{p}} \frac{\partial q}{\partial t}=-\varepsilon_{\mathrm{r}} \frac{\partial c}{\partial t}$

This partial differential equation is replaced by a set of ordinary differential equations following the finite differences method. The backward definition of the finite differences represents the $j$ th slice of the column divided in $N$ slices and with a multiplication by $(-V /$ $N)$ :

$Q\left(c_{j-1}-c_{j}\right)-\frac{m}{N} \frac{\mathrm{d} q_{j}}{\mathrm{~d} t}=\varepsilon_{\mathrm{r}} \frac{V}{N} \frac{\mathrm{d} c_{j}}{\mathrm{~d} t}$

A mass balance of the liquid in the column gives the value of the metal concentration on the resin $q(t)$, which does not depend on the position in the column.

$m \frac{\mathrm{d} q(t)}{\mathrm{d} t}=Q\left(c_{0}-c_{N}\right)-\varepsilon_{r} \frac{V}{N} \sum_{j=1}^{N} \frac{\mathrm{d} c_{j}}{\mathrm{~d} t}$

This equation is solved simultaneously with Eq. (17).

(3) Nearly plug flow behaviour of the liquid with no back mixing of the solid, which is the plug flow model.

The partial differential equation is given by Eq. (17).

For the plug flow with back mixing of the solid and plug flow models, all initial concentrations are equal to zero, except $\mathrm{c}_{j-1}$ in slice $1(N=1)$ which is equal to $c_{0}$. Fig. 8 represents the plug flow and the plug flow with back mixing of solid reactor models developed in this section. 

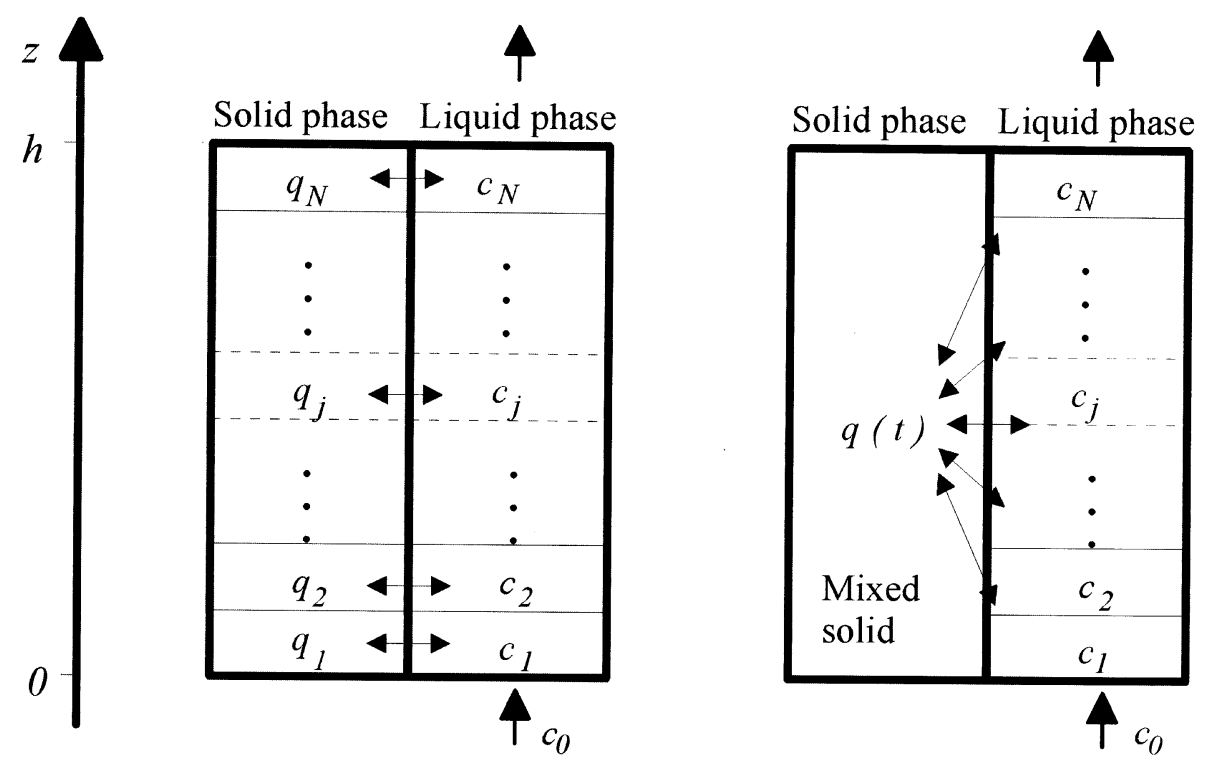

Fig. 8. The plug flow model and the plug flow model with back mixing of the solid.

Fig. 9 compares the three models developed for the representation of the fluidized bed adsorption of metal to the resin Chelamine: the stirred tank model, the plug flow with back mixing of the solid model and the plug flow model; the kinetics, in each case, described by an external transfer limitation model $\left(k_{\mathrm{L}}=2.0 \times 10^{-5} \mathrm{~m}\right.$ $\left.\mathrm{s}^{-1}\right)$.

The first model can be ruled out because the initial outlet concentration versus time is too small compared with the stirred tank model as shown on Fig. 9. The second model leads to a gradual increase of outlet concentration with time, which was not observed. The third model, with relatively low dispersion and no back mixing of the solid can describe the experimental results.

The plug flow model was applied to the four runs presented in Fig. 7. Table 3 gives a summary of the estimated parameters.

The parameter $k_{\mathrm{L}}$, which has a value between $1.0 \times$ $10^{-5} \mathrm{~m} \mathrm{~s}^{-1}$ and $2.0 \times 10^{-5} \mathrm{~m} \mathrm{~s}^{-1}$, is roughly five times lower than those obtained for CSTR adsorptions. It is not surprising since fluidized bed hydrodynamic conditions are much softer than CSTR mechanical stirring.

Numerous correlations to estimate the mass transfer coefficient $k_{\mathrm{L}}$ in a fluidized bed are found in the literature [33-36]. The coefficients $k_{\mathrm{L}}$ calculated for Run 2 conditions with different correlations had the same order of magnitude as the values obtained with the plug flow model simulations.

The plug flow model is usually used for fixed bed experiments: the liquid phase behaves as a plug flow and the solid phase is totally immobile. This model does not consider liquid or solid phase dispersion phe- nomena. Nevertheless, it fits very well to the experimental concentration profile, except near the saturation zone where the simulated concentration $f$ goes up drastically to 1 . The plug flow model was chosen for the fluidized bed adsorption of heavy metal to the resin Chelamine.

Gübeli [24] studied the fluidization of resins with radii distributions. Particles with a large radius remained at the bottom of the column while particles with small radius went to the top of the bed. A wide radii distribution tends to stratify the fluidized bed and also to minimize solid axial dispersion effects, as it was shown for the resin Chelamine. This is particularly true for small bed expansions.

Moritomi et al. [37] showed that the segregation of a binary fluidized mixing (for instance the loaded and unloaded Chelamine particles) depends on the mean radius $r_{\mathrm{p}}$, on the apparent density $\rho_{\text {ap }}$ of each particle, on the superficial velocity $u$ and on the liquid density $\rho$. They provided a segregation map which can predict, for the fluidization of the Chelamine, that the loaded resin remains, for whatever superficial velocity, below the unloaded resin. The metal adsorption provides thus, an additional stratification of the fluidized bed. Selke [38] arrived at the same conclusion for a fluidized bed adsorption of copper to the resin Amberlite IR-120.

\section{Conclusions}

The adsorption of heavy metals to the resin Chelamine is very well described by a model considering a Langmuir isotherm and an adsorption rate governed by film mass transfer. The mass transfer 

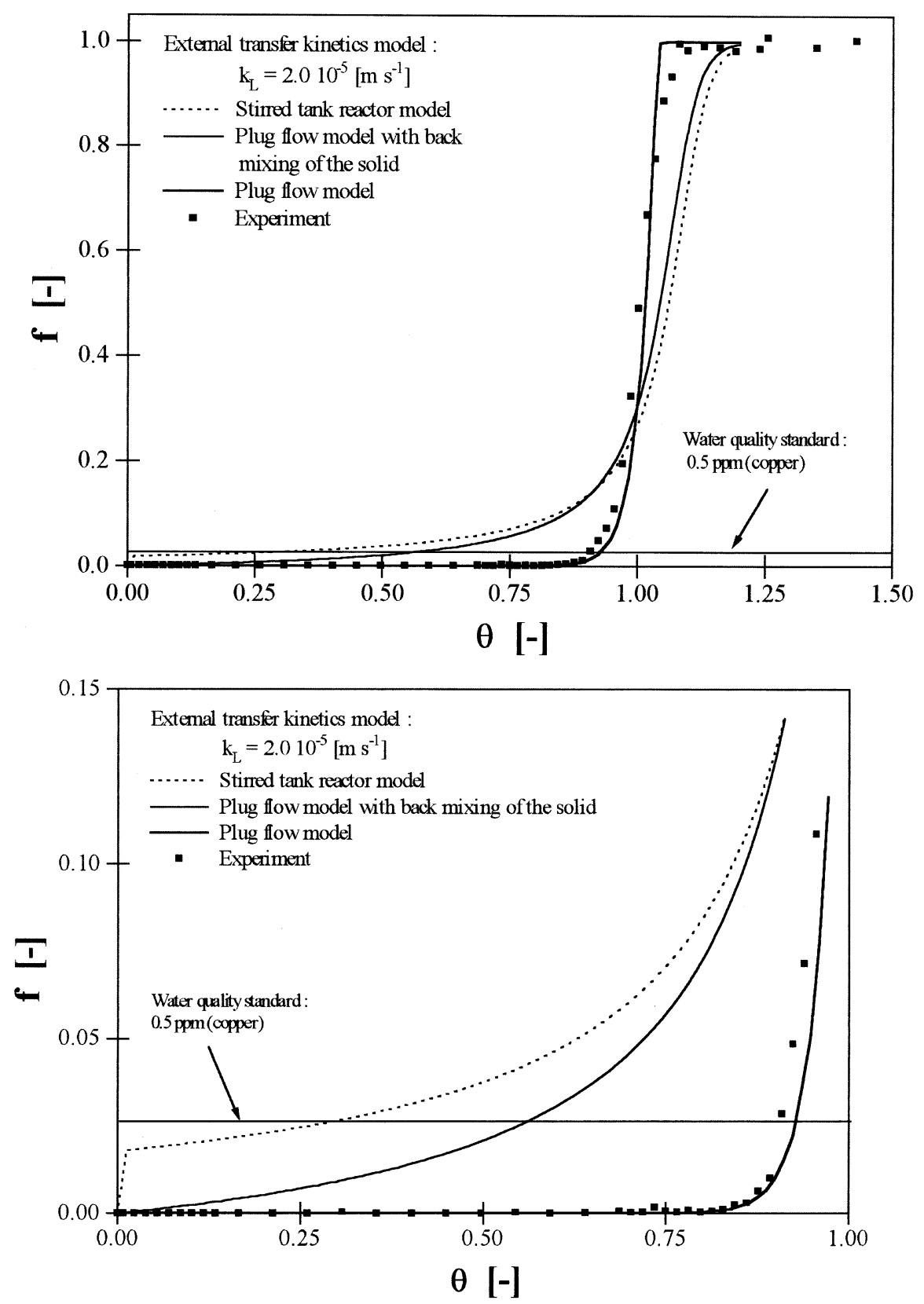

Fig. 9. Adsorption of copper to the resin Chelamine (Run 2); comparison between the stirred tank model, the plug flow model and the plug flow model with back mixing of the solid; external transfer kinetics model.

coefficient $k_{\mathrm{L}}$ is about five times larger in a CSTR than in a fluidized bed. These $k_{\mathrm{L}}$ values correspond to the ones obtained through literature correlations.

The hydrodynamic behaviour depends on the reactor type: an ideal stirred tank model for the CSTR experiments and a plug flow model with immobile solid for the fluidized bed adsorptions. A gradient of resin density, due to the decrease in particle radius with the progress of the metal adsorption, stabilizes the fluidized bed. The natural stratification of the resin allows $90 \%$ use of the resin capacity with an outlet concentration smaller than the water quality standard. If this stratification didn't occur, leading to back mixing of the solid, this proportion drops to $60 \%$. The process STREAMLINETM developed by Pharmacia [39] confers artificially the same property to the solid, which is unevenly weighted down by incorporating quartz in the resin. A further advantage of naturally occurring stratification of the resin Chelamine is if loaded resin has to be withdrawn at the bottom of the reactor for a regeneration in another column. 
Further work is now carried out in a fluidized bed column equipped with internals: higher superficial velocities (up to five time larger than in a classical fluidized bed) can be used for the fluidization of the resin Chelamine. The adsorption model developed in this paper will be applied to experiments done in the modified fluidized bed.

\section{Acknowledgements}

This research is supported by the Swiss Commission for Technology and Innovation (CIT). The authors would like to thank Dr G. Jeanneret (JPS-Chimie, Neuchâtel, Switzerland) for the synthesis of the resin Chelamine Standard ${ }^{\circledR}$ and J.-J. Geering (Institut de radiophysique appliquée, Lausanne, Switzerland) for his advices and help in analysing the samples by atomic absorption spectrometry.

\section{Appendix A. Nomenclature}

$a$

Ar

$c$

$c^{*}$

$c_{i}$

$c_{0}$

$D^{\mathrm{e}}$

$D_{\text {L }}$

DaI

$f$

$h$

$h_{0}$

$k_{\mathrm{f}}$

$k_{\mathrm{L}}$

$k_{\mathrm{r}}$

$K_{\mathrm{d}}$

$m$

$n_{\mathrm{p}}$

$N$ surface of the particles per reactor unit volume $\left(\mathrm{m}^{2} \mathrm{~m}^{-3}\right)$

Archimedes number $=\rho\left(\rho_{\mathrm{ap}}-\rho\right) \mathrm{g} d_{\mathrm{p}}^{3} / \mu^{2}$ the solution $\left(\mathrm{mol} \mathrm{m}^{-3}\right)$ cations concentration in the bulk of the solution at equilibrium $\left(\mathrm{mol} \mathrm{m} \mathrm{m}^{-3}\right)$ cations concentration per unit volume of liquid inside a particle (mol m-3) cations concentration at the inlet of the reactor $\left(\mathrm{mol} \mathrm{m} \mathrm{m}^{-3}\right)$ effective diffusion coefficient $\left(\mathrm{m}^{2} \mathrm{~s}^{-1}\right)$ diffusivity coefficient at infinite dilution $\left(\mathrm{m}^{2} \mathrm{~s}^{-1}\right)$

Damköhler I number $=k_{\mathrm{L}} \mathrm{a} \tau / \varepsilon_{\mathrm{r}}$ normalized cations concentration at the outlet of the reactor fluidized bed height (m) settled bed height (m) forward rate constant $\left(\mathrm{m}^{3} \mathrm{~mol}^{-1} \mathrm{~s}^{-1}\right)$ liquid film mass transfer coefficient $\left(\mathrm{m} \mathrm{s}^{-1}\right)$ reverse rate constant $\left(\mathrm{s}^{-1}\right)$ dissociation constant $\left(\mathrm{mol} \mathrm{m} \mathrm{m}^{-3}\right)$ mass of resin in the reactor $(\mathrm{kg})$ number of particles present in the reactor number of slices (finite differences method) cations concentration in the bulk of

$\begin{array}{ll}Q & \text { flow rate }\left(\mathrm{m}^{3} \mathrm{~s}^{-1}\right) \\ q^{*} & \begin{array}{l}\text { resin loading at equilibrium } \\ \left(\mathrm{mol} \mathrm{kg}^{-1}\right)\end{array} \\ & \text { metal amount per unit weight of } \\ q_{i} & \begin{array}{l}\text { dry resin }\left(\mathrm{mol} \mathrm{kg}^{-1}\right) \\ \text { metal amount per unit weight of } \\ \text { dry resin (in equilibrium with metal }\end{array} \\ q_{0} & \left.\left.\text { concentration } c_{0}\right) \text { (mol } \mathrm{kg}^{-1}\right) \\ & \text { maximum resin capacity }\left(\mathrm{mol} \mathrm{kg} \mathrm{kg}^{-1}\right) \\ q_{\mathrm{m}} & \text { resin radial co-ordinate }(\mathrm{m}) \\ r & \text { mean radius of the particles }(\mathrm{m}) \\ r_{\mathrm{p}} & \text { time (s) } \\ t & \text { liquid superficial velocity }\left(\mathrm{m} \mathrm{s} \mathrm{s}^{-1}\right) \\ u & \text { volume of the reactor }\left(\mathrm{m}^{3}\right) \\ V & \text { column axial co-ordinate }(\mathrm{m}) \\ z & \end{array}$

Greek letters

$\varepsilon_{\mathrm{p}} \quad$ particle porosity

$\varepsilon_{0} \quad$ settled bed porosity

$\varepsilon_{\mathrm{r}} \quad$ reactor porosity

$\varepsilon \quad$ dimensionless time

$\rho_{\text {ap }} \quad$ apparent particle density $\left(\mathrm{kg} \mathrm{m}^{-3}\right)$

$\rho_{\mathrm{p}} \quad$ mass of dry resin per unit volume of swollen particle $\left(\mathrm{kg} \mathrm{m}^{-3}\right)$

$\tau \quad$ reactor residence time (s)

$\tau_{\mathrm{m}} \quad$ reactor molar residence time (s)

\section{References}

[1] P. Menoud, et al., Selective separation and recovery of heavy metals from industrial waste water, in: Proceedings of the International Congress on Recovery Recycling Re-integration (R'95), 1995. Geneva.

[2] V. Schmidt, Développement d'un Système Fluidisé pour la Récupération des Métaux Lourds des Eaux Industrielles par des Résines Chélatantes, 1994, Lausanne, Thèse 1247, EPF.

[3] F. Helfferich, Ion-exchange kinetics. V. Ion exchange accompanied by reactions, J. Phys. Chem. 69 (1965) 1178-1187.

[4] R.S. Juang, H.C. Lin, Metal sorption with extractant,impregnated macroporous resins. 1. Particle diffusion kinetics, J. Chem. Technol. Biotechnol. 62 (2) (1995) 132-140.

[5] R.S. Juang, H.C. Lin, Metal sorption with extractant-impregnated macroporous resins. 2. Chemical-reaction and particle diffusion kinetics, J. Chem. Technol. Biotechnol. 62 (2) (1995) 141-147.

[6] G.M. Rao, A.K. Gupta, Ion exchange processes accompanied by ionic reactions, Chem. Eng. J. 24 (1982) 181-190.

[7] M.G. Rao, et al., Sorption of heavy metal ions on Chelex 100 resin, AIChE Symp. Ser. 78 (219) (1982) 103-111.

[8] J.M. Loureiro, C.A. Costa, A.E. Rodrigues, Recovery of copper, zinc and lead from liquid streams by chelating ion exchange resins, Chem. Eng. Sci. 43 (5) (1988) 1115-1123.

[9] S. Veeraraghavan, L.T. Fan, Modeling adsorption in liquid-solid fluidized beds, Chem. Eng. Sci. 44 (10) (1989) 2333-2344.

[10] M.J. Slater, Principles of Ion Exchange Technology, Butterworth-Heinemann, Oxford, 1991.

[11] B.J. Horstmann, H.A. Chase, Modelling the affinity adsorption of immunoglobulin $\mathrm{G}$ to protein a immobilized to agarose matrices, Chem. Eng. Res. Des. 67 (1989) 243-254. 
[12] B. Biscans, Chromatographie d'échange d'ions en couche fluidisée. Extraction des protéines du lactosérum, Thèse ENSIGC, Toulouse, 1985.

[13] A. Bascoul, Fluidisation liquide-solide. Etude hydrodynamique et extraction des protéines, Thèse ENSIGC, Toulouse, 1989.

[14] N.M. Draeger, H.A. Chase, Modeling of protein adsorption in liquid fluidized beds, in: D.L. Pyle (Ed.), Separations for Biotechnology, vol. 2, Elsevier, London, 1990, pp. 325-333.

[15] S.J. Hwang, W.J. Lu, Ion exchange in a semifluidized bed, Ind. Eng. Chem. Res. 34 (1995) 1434-1439.

[16] Y. Ito, et al., Uranium adsorption characteristics of a circulating fluidized bed adsorber, AIChE J. 38 (6) (1992) 879-886.

[17] A.P. Van der Meer, On counter-current fluidized ion-exchange columns, PhD. Thesis, Delft, 1984.

[18] A. Bascoul, J.P. Couderc, H. Delmas, Movement of solid particles in liquid fluidized-beds, Chem. Eng. Biochem. Eng. J. 51 (3) (1993) 135-150.

[19] M.A. Zarraa, Mass transfert during the removal of dissolved heavy metals from wastewater flows in fluidized beds of ion exchange resins, Chem. Eng. Technol. 15 (1992) 21-25.

[20] B. Biscans, J.P. Riba, J.P. Couderc, Mise en oeuvre de résines échangeuses d'ions en couches fixe et en couche fluidisée multiétagée. Comparaison des deux procédés, Chem. Eng. J. 30 (1985) $81-90$.

[21] B. Biscans, J.P. Riba, J.P. Couderc, Continuous equipment for ion exchange in a fluidized bed. Prospects and problems, Int. Chem. Eng. 28 (2) (1988) 248-256.

[22] H. Carrère, Extraction des protéines du lactosérum par chromatographie d'échange d'ions en lit fluidisé. Modélisation et optimisation, Thèse, ENSIGC, Toulouse, 1993.

[23] F.P. Gailliot, et al., Fluidized bed adsorption for whole broth extraction, Biotechnol. Prog. 6 (1990) 370-375.

[24] P. Gübeli, Séparation de protéines en présence de biomasse par adsorption en lit fluidisé, Thèse 1206, EPF, Lausanne, 1993.
[25] G. Jeanneret-Gris, Brevet Européen n0362325, 1990.

[26] L. Schiller, A. Neumann, Z. Ver. Deut. Ing. 77 (1933) 318.

[27] P. Menoud, Récupération de métaux lourds par une résine chélatante, Thèse 1563, EPF, Lausanne, 1996.

[28] A.E. Martell, R.M. Smith, Critical Stability Constants, Plenum, New York, 1974.

[29] S. Blain, P. Appriou, H. Handel, Preconcentration of trace metals from sea water with the chelating resin Chelamine, Anal. Chim. Acta 272 (1) (1993) 91-97.

[30] P. Harriott, Mass transfer to particles: Part I. Suspended in agitated tanks, AIChE J. 8 (1) (1962) 93-102.

[31] C. Metzdorf, Caractérisation d'un Réacteur Lit Fluidisé Liquidesolide Garni de Mélangeurs Statiques, Thèse 629, EPF, Lausanne, 1986.

[32] Confédération Helvétique, Ordonnance sur le déversement des eaux usées, Ordonnance 814.225.21, 1-16, 1975, pp. 1-16.

[33] T. Koloini, M. Sopcic, M. Zmuer, Mass transfer in liquidfluidized beds at low Reynolds numbers, Chem. Eng. Sci. 32 (1977) 637-641.

[34] T. Koloini, et al., Mass transfer in liquid-fluidized beds at low Reynolds numbers, Chem. Eng. Commun. 5 (1980) 233-244.

[35] P. Tournié, C. Laguerie, J.P. Couderc, Correlations for mass transfer between fluidized spheres and a liquid, Chem. Eng. Sci. 34 (1979) 1247-1255.

[36] P.K. Agarwal, Transport phenomena in multi-particle systems. II. Particle-fluid heat and mass transfer, Chem. Eng. Sci. 43 (9) (1988) 2501-2510.

[37] H. Moritomi, T. Yamagishi, T. Chiba, Predictive of complete mixing of liquid-fluidized binary solid particles, Chem. Eng. Sci. 41 (2) (1986) 297-305.

[38] W.A. Selke, H. Bliss, Continuous countercurrent ion exchange, Chem. Eng. Prog. 47 (10) (1951) 529-533.

[39] Pharmacia, Expanded bed adsorption - a new unit operation, Downstream 14 (1993) 9-12. 